\title{
Effect of wall surface materials on deposition of particles with the aid of negative air ions
}

\author{
Chih Cheng Wu, Grace W.M. Lee*, Pojen Cheng, Shinhao Yang, Kuo Pin Yu \\ Graduate Institute of Environmental Engineering, National Taiwan University, 71, Chou-Shan Road, Taipei 106, Taiwan, ROC
}

Received 17 December 2004; received in revised form 30 May 2005; accepted 31 May 2005

\begin{abstract}
This work studied how wall surface materials influence the removal of airborne particles with negative air ions (NAIs) in indoor environments. Five wall surface materials—stainless steel, wood, PVC (polyvinyl chloride), wallpaper and cement paint - were applied to the inner surface of a test chamber. Two monodispersed solid $\mathrm{NaCl}$ particle sizes, 300 and $30 \mathrm{~nm}$, were tested. The NAIs in the chamber were generated by negatively electric discharge in the range 3000-5000 ions $\mathrm{cm}^{-3}$. Experiments on the natural decay and application of NAIs were conducted at an air exchange rate of $1 \mathrm{~h}^{-1}$. The decay coefficient, the removal efficiency, the time to halve the concentration $\left(T_{50}\right)$ and the effective cleaning rate (ECR) were taken into account. The experimental data revealed that NAIs enhanced the removal of both 300 and $30 \mathrm{~nm}$ particles for each wall surface material. The decay coefficients of the NAI applications $\left(k_{\mathrm{a}}\right)$ were 2.9-7.4 and 2.5-4.0 times higher than those of natural decay $\left(k_{\mathrm{n}}\right)$ for 300 and $30 \mathrm{~nm}$ particles, respectively. However, the effect of the wall surfaces on the removal of particles was observed in both natural decay and NAI application experiments. The order of natural decay for 300 and $30 \mathrm{~nm}$ particles under different wall surfaces was cement paint $>\mathrm{PVC} \cong$ wallpaper $\cong$ wood $>$ stainless steel, as perhaps determined by the roughness of the wall materials. The overall removal efficiencies of 300 and $30 \mathrm{~nm}$ particles during $30 \mathrm{~min}$ of NAI emission were over $60 \%$ and $80 \%$, respectively, in the chamber with wood and PVC wall surfaces. The half concentration times $\left(T_{50}\right)$ of NAI applications for various wall surfaces were less than $20 \mathrm{~min}$, except for stainless steel and cement paint walls. The ECR demonstrated that the net effects of the NAIs for $300 \mathrm{~nm}$ particles followed the order wood $(34.6 \mathrm{Lpm})>$ PVC $(33.3 \mathrm{Lpm})>$ wallpaper $(27.0 \mathrm{Lpm})>$ stainless steel $(16.6 \mathrm{Lpm})>$ cement paint $(14.8 \mathrm{Lpm})$. The ECR for $30 \mathrm{~nm}$ particles followed the order wood $(41.4 \mathrm{Lpm})>$ PVC $(30.4 \mathrm{Lpm}) \cong$ cement paint $(30.3 \mathrm{Lpm})$ $>$ wallpaper $(27.7 \mathrm{Lpm})>$ stainless steel $(20.1 \mathrm{Lpm})$. The NAI could remove particles from the wood and PVC
\end{abstract}

\footnotetext{
* Corresponding author.

E-mail addresses: d89541001@ntu.edu.tw (C.C. Wu), gracelee@ntu.edu.tw (G.W.M. Lee).
} 
wall surfaces substantially more effectively than from other wall materials. The various electrical characteristics and roughness of the wall materials may have been responsible for the associated of the various ECRs with the various wall surface materials.

(c) 2005 Elsevier Ltd. All rights reserved.

Keywords: Negative air ion; Particle deposition; Wall material; Decay coefficient; Electrical property

\section{Introduction}

Negative air ionizers are typically applied to clean air indoors. Daniels (2002) reported that negative air ions (NAIs) reduce aerosol particles, airborne microbes, odors and volatile organic compounds (VOCs) in indoor air. The removal of aerosol particles using NAIs is efficient (Grabarczyk, 2001; Wu \& Lee, 2003). The mechanisms of particle removal by NAI include particle charging by emitted ions and electromigration (Lee, Yermakov, \& Grinshpun, 2004a,b). The charged aerosol particles and the electric field produced by the electrical discharge increase the migration velocity towards the indoor surfaces (Lee et al., 2004a,b; Mayya, Sapra, Khan, \& Sunny, 2004). Particles are finally deposited on indoor surfaces, such as wall surfaces. The deposition of particles on various wall materials has been studied. A glass chamber (Crump, Flagan, \& Seinfeld, 1983), an acrylic chamber (Okuyama, Kousaka, Yamamoto, \& Hosokawa, 1986), Teflon film bags (McMurry \& Rader, 1985) and aluminized Mylar bags (Cooper, Langer, \& Rosinski, 1979) have been used, but the effects of various wall materials has not been considered. Although many decorating materials are used in rooms, few studies have evaluated the effect of wall surface materials on the removal of particles by NAIs.

These NAIs are negatively charged small airborne ions with an average electric mobility of $1-2 \mathrm{~cm}^{2} \mathrm{~V}^{-1} \mathrm{~s}^{-1}$ (Krueger \& Reed, 1976). Luts and Salm (1994) indicated that superoxide $\left(\mathrm{O}_{2}^{-}\right)$is the primary negatively charged NAI species and is more stable than other NAIs (Goldstein, Goldstein, \& Merzlyak, 1992; Kosenko, Kaminsky, Stavrovskaya, Sirota, \& Kondrashova, 1997). The typical lifetime of NAIs in clean air is approximately 100 s (Parts \& Luts (2004); Daniels, 2002). Kondrashova et al. (2000) indicated the beneficial biological effects of NAIs. Furthermore, studies have investigated the application of NAIs in hypertension therapy and the role of NAIs in promoting recovery from stress- and exercise-based injuries (Kondrashova et al., 2000; Ryushi et al., 1998).

Particles in indoor air are deposited following transport to the boundary layer of the surfaces in a room. Crump and Seinfeld (1981) studied a wall deposition theory of particles in an enclosed vessel explained the motion of aerosol by turbulent transport, Brownian diffusion and gravitational sedimentation. Park, Kim, Han, Kwon, and Lee (2001) investigated the loss rate of polydispersed aerosols from a wall, correcting the model of Crump and Seinfeld (1981) for the polydispersity effects of polydispersed aerosols. Park et al. (2001) found that the wall loss rate of polydispersed aerosols exceeded that of monodispersed aerosols. McMurry and Rader (1985) proposed a wall deposition theory of particles in spherical, electrically charged chambers, for aerosol moved by electrostatic drift, or exhibiting turbulent movement, Brownian diffusion and gravitational sedimentation. The study conclusively established that electrostatic effects dominate for 0.005-1.0 $\mu \mathrm{m}$ particles. Nomura, Hopke, Fitzgerald, and Mesbah (1997) investigated the deposition of particles in a chamber as a function of size and ventilation rate, and indicated that the approach of Benes and Holub (1996) provided a more reasonable fit to the experimental data than the model of Crump and Seinfeld (1981). However, models for estimating the deposition of particles on a 
wall are incomplete, unless they take into account convective flows, wall roughness, ventilation and the condition of the surfaces (John, 1995; Nomura et al., 1997).

The removal of aerosol particles by applying NAIs involves charging particles, and their electromigration from air to wall surfaces. Wiedensohler et al. (1994) and Adachi, Kousaka, and Okuyama (1985) indicated that particle charging efficiency depends on the residence time of the particles and the ion concentration. Unger, Boulaud, and Borra (2004) and Oh, Park, and Kim (2004) reported that particle charging is affected by the shapes of particles. Particle charges are also limited by particle material (Wiedensohler et al., 1994). The velocity of particle electro-migration is dependent on particle size, amount of particle charge and the intensity of the electrical field. Lee et al.(2004a,b) indicated that the mobility and removal efficiency of aerosol particles increased with an increase in NAI emission rates. Conversely, if the NAI concentration is too high, an electrostatic shield on wall surfaces is produced that prohibits the deposition of charged particles, especially when surface materials have low-level conductivity (Lee et al., 2004a,b). Therefore, NAI concentration in this study was kept at a moderate concentration by utilizing a stable electrical discharge process. However, the factors relating to particle charging, electro-migration, etc., were carefully considered for the investigation of the influence of wall surface materials on removal of aerosol particles by application of NAI.

\section{Materials and method}

Five wall surface materials (stainless steel, wooden board, PVC board, wallpaper and cement paint) were chosen as the wall materials in this study of the effect of wall surface materials on NAI particle deposition with NAIs in a reaction chamber. Two sizes of $\mathrm{NaCl}$ monodisperse solid particles, 300 and $30 \mathrm{~nm}$, were generated as the target particles.

\subsection{Materials}

Sodium chloride $(\mathrm{NaCl})$ was obtained from Riedel-deHaën (purity $>99.8 \%$ ). The experimental chamber was made of stainless steel (SUS-304). The wall surface materials used were plywood board, PVC (polyvinyl chloride) board, paper-fiber-based wallpaper, and cement-painted board made of water-based cement paint (ICI Ltd.) on a wooden board. The wooden board, PVC board, wallpaper and cement paint were purchased from B\&Q. Six boards of each wall material were prepared except for stainless steel, measuring $1 \mathrm{~m} \times 1 \mathrm{~m}$. The electrical conductivity and surface resistivity of four wall materials (wood, wallpaper, cement paint and PVC) were measured by the appointed firm, SGS Taiwan Ltd. using the ASTM D257 method. The data were surface resistivity $(\Omega)$ : wood $\left(3.97 \times 10^{15}\right)>$ PVC $\left(3.11 \times 10^{15}\right)>$ wallpaper $\left(1.03 \times 10^{15}\right)>$ cement paint $\left(5.96 \times 10^{11}\right) \gg$ stainless steel (conductor) and electrical conductivity $(\Omega \mathrm{m})^{-1}$ : wood $\left(1.24 \times 10^{-15}\right)<\operatorname{PVC}\left(2.38 \times 10^{-15}\right)<$ wallpaper $\left(4.17 \times 10^{-15}\right)<$ cement paint $\left(2.54 \times 10^{-9}\right) \ll$ stainless steel $\left(1.4 \times 10^{6}\right.$; Callister, 2000). Moreover, the order of the roughness of the wall materials was cement paint $>$ wood $\cong$ wallpaper $\cong \mathrm{PVC}>$ stainless steel.

\subsection{Experimental system}

Fig. 1 shows the four-part experimental system: a clean air supply assembly; a monodisperse particle generation assembly; a reaction chamber; and, a particle monitoring instrument. Compressed air, 


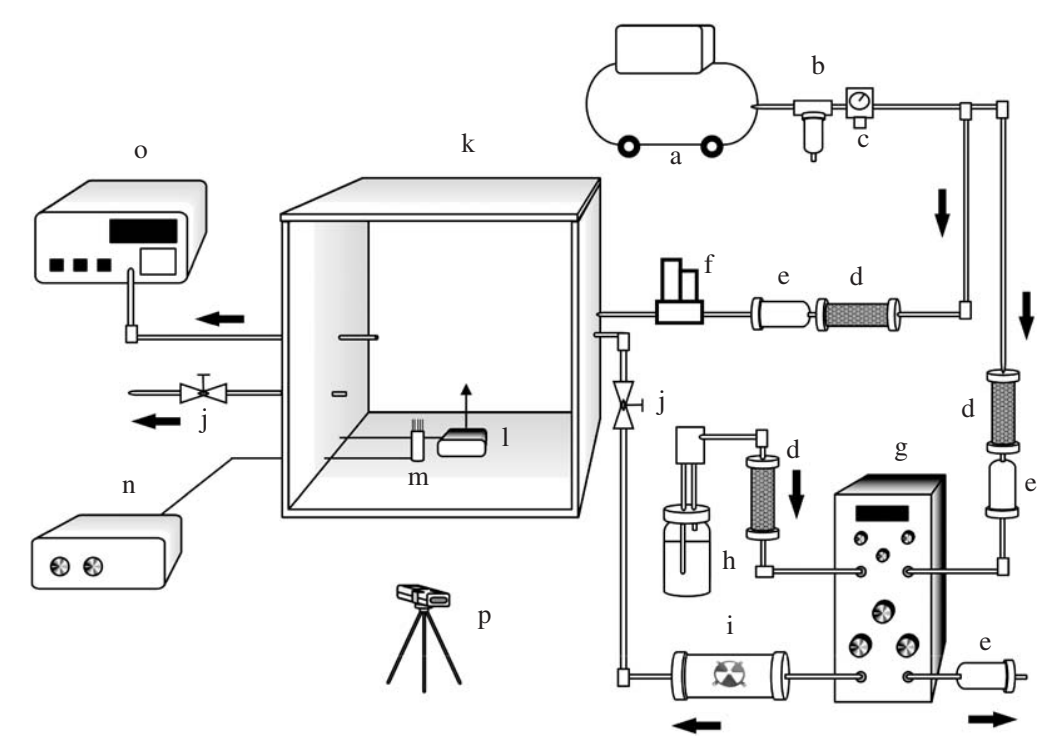

Fig. 1. Illustration of experimental system (a) air compressor (b) water trapper (c) pressure controller (d) diffusion dryer filled silica gel (e) HEPA (f) mass flow controller (g) electrostatic classifier (h) Constant Output Atomizer (i) Aerosol Neutralizer with $\mathrm{Kr}-85$ (j) switch valve (k) chamber (l) fan (m) NAI generator (n) power supply (o) Condensation Particle Counter (p) air ion counter.

generated by an air compressor and passed through a water trapper and a pressure controller, was employed as the clean air source. The compressed air was then passed through a diffusion dryer filled with silica gel that maintained relative humidity at $40-45 \%$ and a HEPA filter that removed particles from the compressed air. The clean air supply had two branches. The flow rate of one branch entering chamber was controlled by a mass flow controller (Model 860, SIERRA, CA, USA) and was applied to clean the chamber prior to experiments and provide ventilation during experiments. The other branch supplied clean air for generating monodisperse particles. The monodisperse particle generation system consisted of a particle generator and a particle classifier. The polydisperse droplet of $\mathrm{NaCl}$ was produced by utilizing Constant Output Atomizer (Model 3076, TSI, St. Paul, MN, USA) to a solution of $2.0 \% \mathrm{NaCl}$ in deionized water. The polydisperse droplet processed through a diffusion dryer became a polydisperse solid $\mathrm{NaCl}$ particle, which was then classified into monodisperse (300 or $30 \mathrm{~nm}$ ) particles with an Electrostatic Classifier (Model 3071A, TSI, St. Paul, MN, USA). The electrostatic charge of particles was neutralized by a Kr-85 neutralizer (Model 3077, TSI, St. Paul, MN, USA). The neutralized monodisperse target particles were passed through a switch valve before entering the reaction chamber.

The reaction chamber was a closed system with four connecting tubes and an inner dimension of $1.0 \mathrm{~m}(\mathrm{~L}) \times 1.0 \mathrm{~m}(\mathrm{~W}) \times 1.0 \mathrm{~m}(\mathrm{H})$. It was made of stainless steel (SUS-304) and earthed. The inlets of clean air and monodisperse target particles were connected on one side of the chamber. On the opposite chamber side, a tube with a switch valve for pressure balance and an outlet for monitoring particle concentrations with Condensation Particle Counter (CPC) (Model 3025, TSI, St. Paul, MN, USA) were installed. In the reaction chamber, a fan $(12 \mathrm{~cm}(\mathrm{~L}) \times 12 \mathrm{~cm}(\mathrm{~W}) \times 5 \mathrm{~cm}(\mathrm{H}))$ was set on the bottom in the center of the chamber for well air mixing. An NAI generator with a negative 
electric discharge was placed near the fan. The electrode of the generator was a cluster of copper needles; the discharge voltage was controlled with a power supply (Model SL300, SPELLMAN, USA) located outside the chamber. Different wall materials were fixed to the chamber's inner surfaces under different experimental conditions. A CPC monitored particle concentration through a sampling tube of $10 \mathrm{~cm}$ length placed in the chamber. Interference of near-wall effect was eliminated by employing this $10 \mathrm{~cm}$ tube.

\subsection{Experimental procedure}

During preliminary experiments, the air mixing ratio, and NAI concentration and distribution in chamber were examined. The air mixing ratio experiments were performed twice by applying a $\mathrm{CO}_{2}$ gas tracer during fan operation. When the $\mathrm{CO}_{2}$ concentration was consistent and around $5000 \mathrm{ppm}$ in the chamber, clean air was forced into the chamber at a constant rate of $16.7 \mathrm{Lpm}$ creating an air exchange rate of $1 \mathrm{~h}^{-1}$. The concentration of $\mathrm{CO}_{2}$ was monitored with Q-Trak (Model 8551, TSI, St. Paul, MN, USA) at the chamber outlet for $30 \mathrm{~min}$. The air mixing ratio of the chamber (ASTM D5116-97, 1997) is calculated as

$$
\eta_{\operatorname{mix}}=\left\{1-\frac{\sum_{i=1}^{n}\left[\left|C_{\mathrm{a}}\left(t_{i}\right)-C\left(t_{i}\right)\right| \times\left(t_{i}-t_{i-1}\right)\right]}{\sum_{i=1}^{n}\left[C\left(t_{i}\right) \times\left(t_{i}-t_{i-1}\right)\right]}\right\} \times 100 \%
$$

where $\eta_{\text {mix }}$ denotes mixing ratio (\%); $t_{i}$ and $t_{i-1}$ are sampling time (min), $C_{\mathrm{a}}\left(t_{i}\right)$ stands for $\mathrm{CO}_{2}$ concentration at the chamber outlet (ppm); and, $C\left(t_{i}\right)$ means $\mathrm{CO}_{2}$ concentration (ppm) at completely mixing, which is calculated as $C\left(t_{i}\right)=C_{0} \exp \left(-t_{i}\right)$ for an air exchange rate of $1 \mathrm{~h}^{-1}$. The NAI concentration and distribution in chamber was measured at $25^{\circ} \mathrm{C}$, under $1 \mathrm{~atm}$ and relative humidity of $40-45 \%$. The NAI concentration was adjusted by discharge voltage from the power supply. The NAI concentration was detected with an ion counter (Model ITC-201A, ANDES, Japan) that can detect NAIs and positive air ions (PAIs) concentrations, relative humidity and temperature. The resolution of the ion counter is \pm 10 ion $\mathrm{cm}^{-3}$, ranging between 10 and $1.26 \times 10^{6}$ ion $\mathrm{cm}^{-3}$; the data were captured every $2 \mathrm{~s}$. When the discharge voltage was $5.0 \mathrm{kV}$, the NAI concentration was approximately $3000-5000 \mathrm{ion} \mathrm{cm}^{-3}$ in clean air.

Before each experiment, the chamber was cleaned using an air jet and electrostatic cleaning paper. Then, the reaction chamber's six inner surfaces were covered with one of the wall materials. The chamber was then closed; clean air was input into the chamber and the fan was started. When the particle concentration was under $200 \mathrm{~cm}^{-3}$, the negative air ionizer was turned on and the NAI concentration checked. The ionizer was then turned off and the clean air inlet was closed. The monodispersed $\mathrm{NaCl}$ target particles were input into the chamber to increase the particle concentration. When it reached between 16,000 and $18,000 \mathrm{~cm}^{-3}$, the particle generator was turned off and the valve through which particles entered the chamber was closed. The negative air ionizer was turned on to begin the experiment and clean air was simultaneously input to the chamber at an inflow rate of $16.7 \mathrm{Lpm}$, maintaining an air exchange rate of $1 \mathrm{~h}^{-1}$. On the opposite side of chamber, a switch valve was opened to exhaust the air. The concentration of $\mathrm{NaCl}$ particles was measured three times per second using the $\mathrm{CPC}$ for over $30 \mathrm{~min}$ with and without NAI under experimental conditions. 


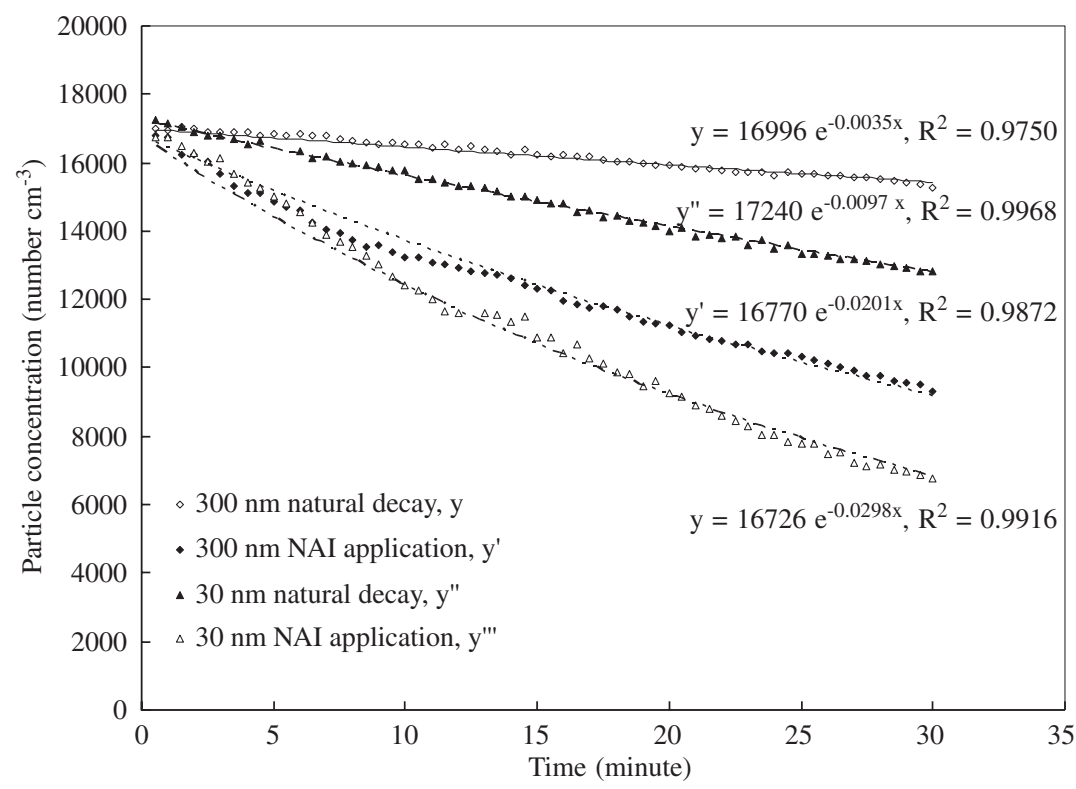

Fig. 2. Particle concentration decay of 300 and $30 \mathrm{~nm}$ particles with natural decay and NAI application during $30 \mathrm{~min}$ in chamber with wall surface of stainless steel.

\section{Results and discussion}

Preliminary experimental results showed that the mixing ratios of air in chamber were $83.2 \%$ and $84.0 \%$, which is over $80 \%$ for the chamber to meet the well mixed condition (ASTM D5116-97, 1997).

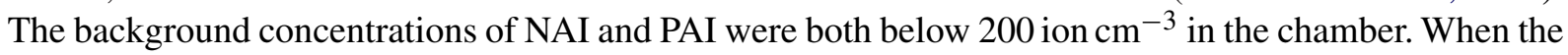
NAIs were generated, PAIs were undetectable because the NAIs neutralized the PAIs. The NAI concentration decreased with the distance from discharge electrode increased. For example, NAI concentrations averaged 5162 ion $\mathrm{cm}^{-3}$ and 3347 ion $\mathrm{cm}^{-3}$ at a distance of 10 and $50 \mathrm{~cm}$ from the discharge electrode, respectively. Furthermore, NAI concentration decreased with an increase in particle concentration in the chamber, a result of NAIs reacting with particles. The level of NAI concentration decreased by about 1000 ion $\mathrm{cm}^{-3}$ when the particle concentration was between 16,000 and 18,000 number $\mathrm{cm}^{-3}$. Even though NAI concentrations varied with particle concentrations in the chamber, the NAI concentration in experiments was controlled by introducing clean air.

\subsection{Decay coefficient}

Figs. 2, 3, 4, 5 and 6 plot the concentrations of 300 and $30 \mathrm{~nm}$ particles versus time under natural decay and NAI application over $30 \mathrm{~min}$ for stainless steel, wood, PVC, wallpaper and cement paint, respectively. The results in Figs. 2-6 reveal that the reduction in particle concentrations when NAI was applied exceeded that associated with natural decay. The natural decay of $30 \mathrm{~nm}$ particles was faster than that of $300 \mathrm{~nm}$ particles. The order of particle concentration decays was natural decay of $300 \mathrm{~nm}$ particles $<$ natural decay of $30 \mathrm{~nm}$ particles $<300 \mathrm{~nm}$ particles with NAI applied $<30 \mathrm{~nm}$ particles with 


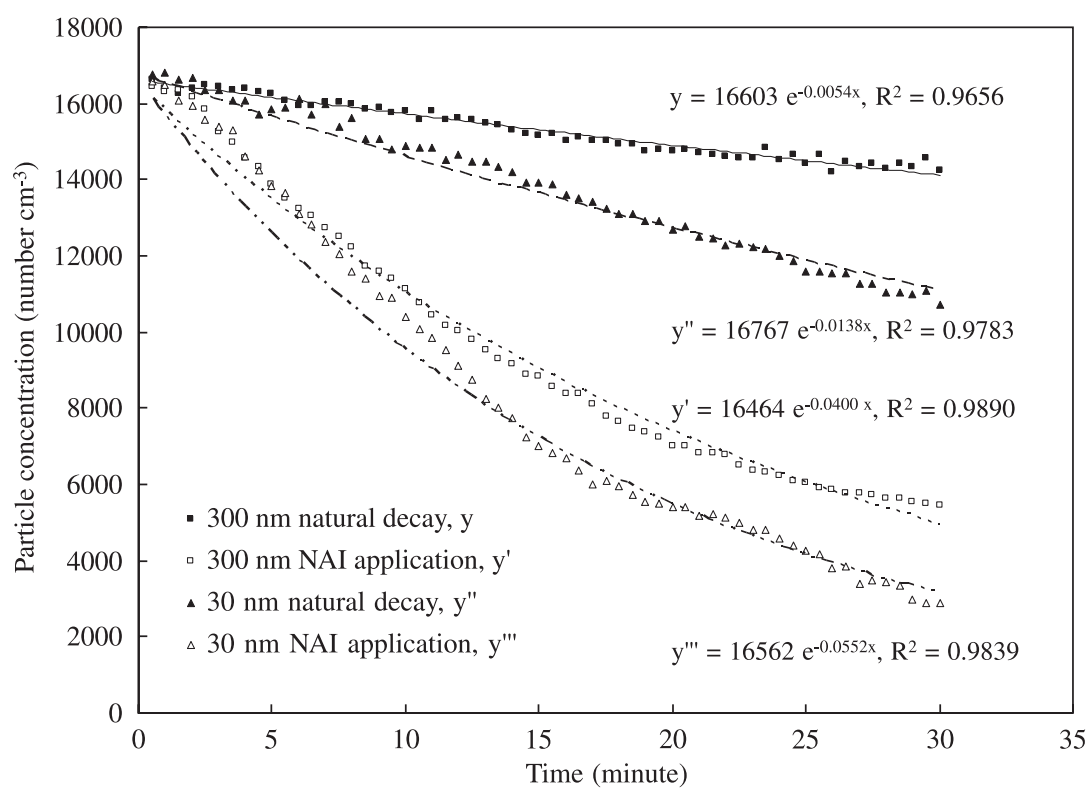

Fig. 3. Particle concentration decay of 300 and $30 \mathrm{~nm}$ particles with natural decay and NAI application during $30 \mathrm{~min}$ in chamber with wooden wall.

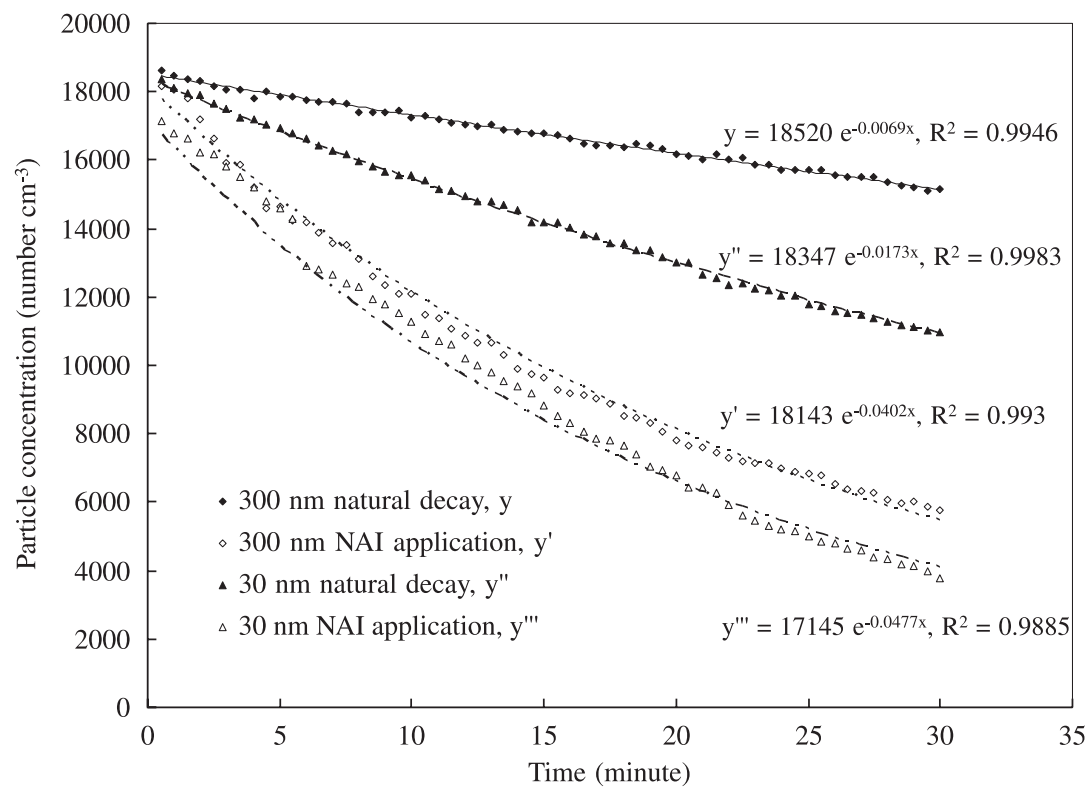

Fig. 4. Particle concentration decay of 300 and $30 \mathrm{~nm}$ particles with natural decay and NAI application during $30 \mathrm{~min}$ in chamber with PVC wall. 


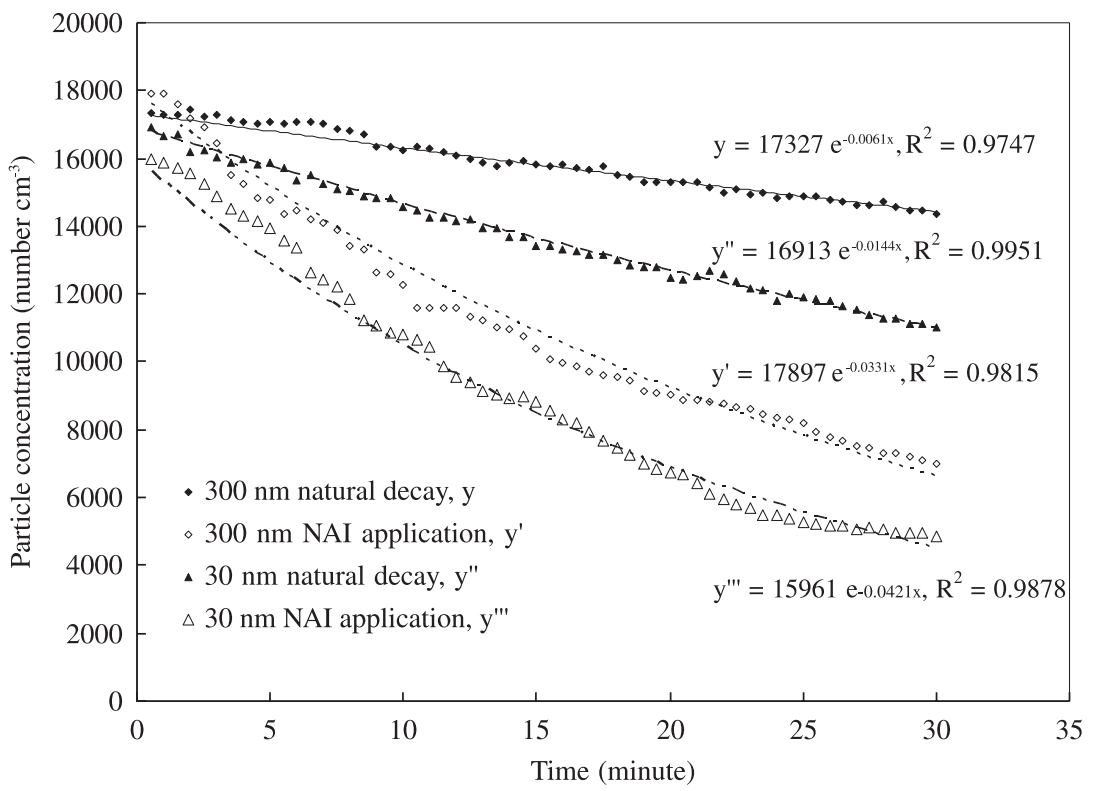

Fig. 5. Particle concentration decay of 300 and $30 \mathrm{~nm}$ particles with natural decay and NAI application during $30 \mathrm{~min}$ in chamber with wallpapered wall.

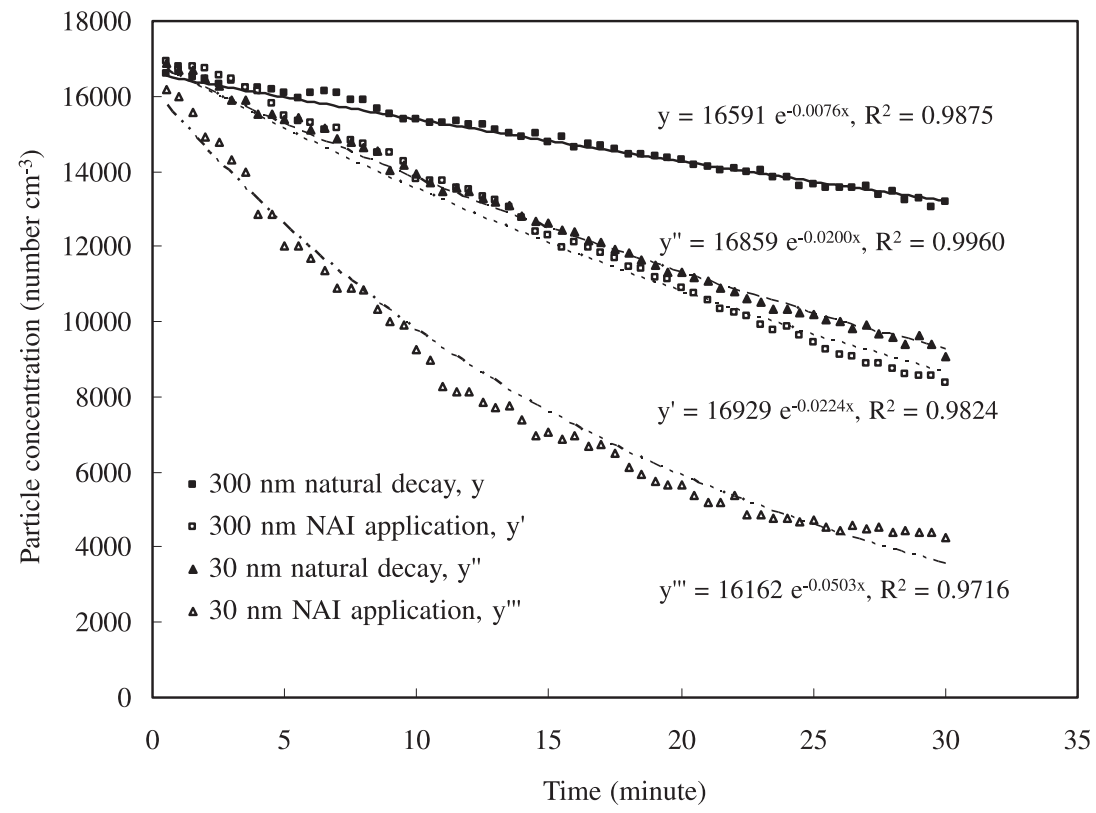

Fig. 6. Particle concentration decay of 300 and $30 \mathrm{~nm}$ particles with natural decay and NAI application during 30 min in chamber with cement-paint coated wall. 
Table 1

Decay coefficients $(k)$ of 300 and $30 \mathrm{~nm}$ particle with natural decay and NAI application $\left(k_{\mathrm{n}}\right.$ and $\left.k_{\mathrm{a}}\right)$ at various wall surface materials (standard deviation less than $15 \%, N=3-5$ )

\begin{tabular}{|c|c|c|c|c|}
\hline \multirow[t]{3}{*}{ Wall surface material } & \multicolumn{4}{|c|}{ Decay coefficient $k\left(10^{-2} \min ^{-1}\right)$} \\
\hline & \multicolumn{2}{|l|}{$300 \mathrm{~nm}$} & \multicolumn{2}{|l|}{$30 \mathrm{~nm}$} \\
\hline & $k_{\mathrm{n}}$ & $k_{\mathrm{a}}$ & $k_{\mathrm{n}}$ & $k_{\mathrm{a}}$ \\
\hline Stainless steel & $0.35 \pm 0.05$ & $2.01 \pm 0.06$ & $0.97 \pm 0.09$ & $2.98 \pm 0.06$ \\
\hline Wood & $0.54 \pm 0.07$ & $4.00 \pm 0.09$ & $1.38 \pm 0.06$ & $5.52 \pm 0.13$ \\
\hline PVC & $0.69 \pm 0.08$ & $4.02 \pm 0.05$ & $1.73 \pm 0.06$ & $4.77 \pm 0.05$ \\
\hline Wallpaper & $0.61 \pm 0.05$ & $3.31 \pm 0.12$ & $1.44 \pm 0.09$ & $4.21 \pm 0.08$ \\
\hline Cement paint & $0.76 \pm 0.09$ & $2.24 \pm 0.03$ & $2.00 \pm 0.08$ & $5.03 \pm 0.12$ \\
\hline
\end{tabular}

NAI applied. The experimental data proved that the order of particle concentration decay was the same for each wall material. The decay curves of particle concentration were more difficult to compare than the rates of particle removal. Therefore, particle concentration decay was analyzing using the following equations:

$$
\begin{aligned}
& \mathrm{d} C / \mathrm{d} t=-k C, \\
& C_{\mathrm{t}}=C_{0} \exp (-k t), \quad k=k_{\mathrm{n}} \text { or } k_{\mathrm{a}},
\end{aligned}
$$

where $C$ is the particle concentration (number $\mathrm{cm}^{-3}$ ); $C_{0}$ and $C_{\mathrm{t}}$ are the initial concentration of target particles and the concentration thereof at time $t$, respectively $\left(\right.$ number $\left.\mathrm{cm}^{-3}\right) ; t$ is the residence time (min); $k$ is the decay coefficient of particle concentration $\left(\mathrm{min}^{-1}\right)$; and, $k_{\mathrm{n}}$ and $k_{\mathrm{a}}$ are the decay coefficients of particle concentration associated with natural decay and NAI, respectively $\left(\mathrm{min}^{-1}\right)$. The coefficients of $C_{0}, C_{\mathrm{t}}$ and $t$ were measured in each experiment. The decay coefficient $(k)$ is a regression coefficient in an exponential regression analysis, specified by Eq. (3). The subscripts of $k_{\mathrm{n}}$ and $k_{\mathrm{a}}$ refer to natural decay and NAI, respectively. Figs. 2-6 show the regression equations of particle concentration decay. The results of the regression analysis showed that the correlation coefficients for decay of particle concentration versus time all exceeded 0.9650 . Table 1 summarizes $k_{\mathrm{a}}$ and $k_{\mathrm{n}}$ for each wall material and size of particles. Each decay coefficient was an average over three to five repeats; the standard deviations of decay coefficients were less than $15 \%$. The data showed that the $k_{\mathrm{n}}$ values for the natural decay of the $300 \mathrm{~nm}$ particles followed the order cement paint $>\mathrm{PVC} \cong$ wallpaper $\cong$ wood $>$ stainless steel. The corresponding values for the $30 \mathrm{~nm}$ particles followed the same order. The results indicated that the natural decay of particles depended on the wall material and particles of both sizes followed the same trend. Additionally, the roughness of the wall materials followed the order cement paint $>$ wood $\cong$ wallpaper $\cong \mathrm{PVC}>$ stainless steel. The roughness of cement paint exceeded that of the other wall materials and may have been responsible for the relatively high natural decay coefficient $\left(k_{\mathrm{n}}\right)$. Furthermore, the $k_{\mathrm{n}}$ for the $30 \mathrm{~nm}$ particles was larger than the $k_{\mathrm{n}}$ for the $300 \mathrm{~nm}$ particles for every wall material, meaning the $30 \mathrm{~nm}$ particles was more easily removed by natural decay than that of $300 \mathrm{~nm}$ particles. The decay of particle concentration under NAI application was higher than that for natural decay. The $k_{\mathrm{a}}$ was 2.9-7.4 times larger than $k_{\mathrm{n}}$ for the $300 \mathrm{~nm}$ particles. The $k_{\mathrm{a}}$ was $2.5-4.0$ times larger than $k_{\mathrm{n}}$ for the $30 \mathrm{~nm}$ particles. The experimental results showed that NAIs improved the removal of 300 and $30 \mathrm{~nm}$ particles for all 
Table 2

Calculations of decay coefficients of natural decay $\left(k_{\mathrm{n}}\right)$ and NAI application $\left(k_{\mathrm{a}}\right)$ for 300 and 30 nm particle at various wall surface materials

\begin{tabular}{lllll}
\hline Wall surface material & \multicolumn{5}{l}{ Calculations of decay coefficient } \\
\cline { 2 - 5 } & $k_{\mathrm{n}}(300 \mathrm{~nm}) / k_{\mathrm{n}}(30 \mathrm{~nm})$ & $k_{\mathrm{a}}-k_{\mathrm{n}}(300 \mathrm{~nm})$ & $k_{\mathrm{a}}-k_{\mathrm{n}}(30 \mathrm{~nm})$ & $k_{\mathrm{a}}-k_{\mathrm{n}}(300 \mathrm{~nm}) / k_{\mathrm{a}}-k_{\mathrm{n}}(30 \mathrm{~nm})$ \\
\hline Stainless steel & 0.36 & 1.66 & 2.01 & 0.82 \\
Wood & 0.39 & 3.46 & 4.14 & 0.84 \\
PVC & 0.40 & 3.33 & 3.04 & 1.10 \\
Wallpaper & 0.42 & 2.70 & 2.77 & 0.97 \\
Cement paint & 0.38 & 1.48 & 3.03 & 0.49 \\
\hline
\end{tabular}

wall materials. The order of decay coefficient $\left(k_{\mathrm{a}}\right)$ of $300 \mathrm{~nm}$ particles was $\mathrm{PVC}>$ wood $>$ wallpaper $>$ cement paint $>$ stainless steel. The maximum $k_{\mathrm{a}}(300 \mathrm{~nm})$ was 2.0 times larger than the minimum $k_{\mathrm{a}}$ $(300 \mathrm{~nm})$ for the five wall materials. The order of decay coefficient $\left(k_{\mathrm{a}}\right)$ of $30 \mathrm{~nm}$ particles was wood $>$ cement paint $>$ PVC $>$ wallpaper $>$ stainless steel. The maximum $k_{\mathrm{a}}(30 \mathrm{~nm})$ was 1.8 times larger than the minimum $k_{\mathrm{a}}(30 \mathrm{~nm})$.

Table 2 shows the calculations of $k_{\mathrm{n}}$ and $k_{\mathrm{a}}$ for comparing natural decay and NAI application for 300 and $30 \mathrm{~nm}$ particles. The ratio $k_{\mathrm{n}}(300 \mathrm{~nm}) / k_{\mathrm{n}}(30 \mathrm{~nm})$ reflects the differences in natural decay for particle sizes of 300 and $30 \mathrm{~nm}$. Furthermore, $k_{\mathrm{n}}(300 \mathrm{~nm})$ and $k_{\mathrm{n}}(30 \mathrm{~nm})$ differed for various wall materials. However, the ratios of $k_{\mathrm{n}}(300 \mathrm{~nm})$ and $k_{\mathrm{n}}(30 \mathrm{~nm})$ approached a constant value of $0.39 \pm 0.03$ for the five wall materials, meaning the natural decay of $300 \mathrm{~nm}$ particles was 0.39 times that of $30 \mathrm{~nm}$ particles for each wall material. The calculation of $k_{\mathrm{a}}(300 \mathrm{~nm})-k_{\mathrm{n}}(300 \mathrm{~nm})$ obtains the net effect of NAI application for the $300 \mathrm{~nm} \mathrm{NaCl}$ particles. The maximum net effect of NAI application for $300 \mathrm{~nm}$ particles was for wood walls and the minimum net effect of NAI application was for cement-paint walls. The calculation $k_{\mathrm{a}}(30 \mathrm{~nm})-k_{\mathrm{n}}(30 \mathrm{~nm})$ obtains the net effect of NAI application for the $30 \mathrm{~nm} \mathrm{NaCl}$ particles. The maximum net effect under NAI application for $30 \mathrm{~nm}$ particles was with wood walls and the minimum net effect was for stainless steel walls. The results proved that the maximum net effect under NAI application for particle sizes of 300 and $30 \mathrm{~nm}$ was with wood walls. The calculation of $\left[k_{\mathrm{a}}(300 \mathrm{~nm})-k_{\mathrm{n}}(300 \mathrm{~nm})\right]$ $/\left[k_{\mathrm{a}}(30 \mathrm{~nm})-k_{\mathrm{n}}(30 \mathrm{~nm})\right]$ indicates the ratio of NAI net effect of $300 \mathrm{~nm}$ to that of $30 \mathrm{~nm}$. The value of $\left[k_{\mathrm{a}}(300 \mathrm{~nm})-k_{\mathrm{n}}(300 \mathrm{~nm})\right] /\left[k_{\mathrm{a}}(30 \mathrm{~nm})-k_{\mathrm{n}}(30 \mathrm{~nm})\right]$ for PVC wall material was 1.10 , meaning the net NAI effect for $300 \mathrm{~nm}$ particles was better than that of $30 \mathrm{~nm}$ particles. The values for wallpaper, wood, stainless steel and cement-paint walls were $0.97,0.84,0.82$ and 0.49 , respectively. A ratio value less than 1 denotes that the NAI net effect for $30 \mathrm{~nm}$ particles was better than that for $300 \mathrm{~nm}$ particles. The ratio value of 0.49 for the cement-paint walls indicates that the NAI net effect of $30 \mathrm{~nm}$ particles was about two times the NAI net effect of $300 \mathrm{~nm}$ particles.

\subsection{Removal efficiency}

Fig. 7 shows the removal efficiencies for 300 and $30 \mathrm{~nm}$ particles in chamber with different wall surface materials for $30 \mathrm{~min}$. The particle removal efficiency was estimated with the following equation:

$$
\eta_{\mathrm{t}}=\left[\left(C_{0}-C_{\mathrm{t}}\right) / C_{0}\right] \times 100 \%,
$$




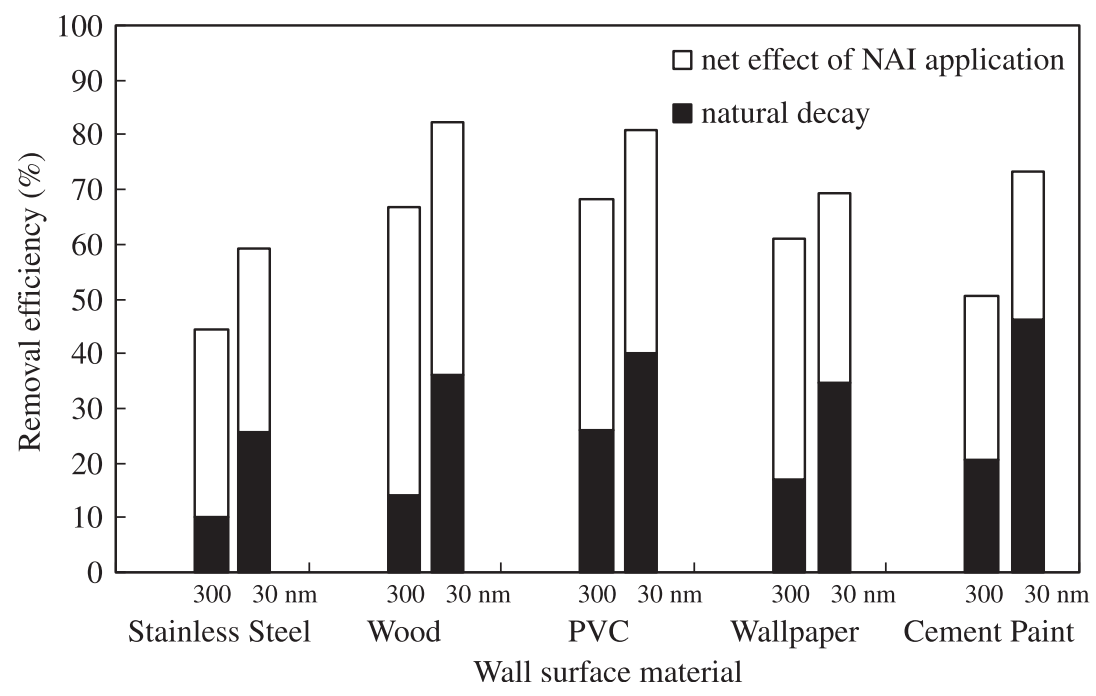

Fig. 7. Removal efficiency of target particle with natural decay and NAI application during 30 min at various particle sizes and different wall surface materials.

where $\eta_{\mathrm{t}}$ is the removal efficiency of target particle $(\%) ; C_{0}$ is initial concentration of target particles (number $\left.\mathrm{cm}^{-3}\right) ; C_{\mathrm{t}}$ is the particle concentration at $30 \mathrm{~min}\left(\right.$ number $\left.\mathrm{cm}^{-3}\right)$. The histogram in Fig. 7 contains removal efficiency for application of NAI and removal efficiency for natural decay. The overall removal efficiency is the combination of the removal efficiencies of NAI application and natural decay. The highest overall removal efficiency for $300 \mathrm{~nm}$ particles was $68.2 \%$ for PVC wall surface material; the second-highest removal efficiency was for wood walls (66.8\%); and, the lowest removal efficiency was for stainless steel walls (44.4\%). The removal efficiency of net effect of NAI application shows that the highest removal efficiency was $52.7 \%$ in wood walls; the second-highest removal efficiency was for wallpaper walls; and, the lowest removal efficiency was cement-paint walls (29.9\%). The highest overall removal efficiency for $30 \mathrm{~nm}$ particles was $82.5 \%$ with wood walls; the second highest overall removal efficiency was with PVC walls (81.2\%); and, the lowest removal efficiency was with stainless steel walls (59.6\%). The experimental results of NAI removal efficiency demonstrates that the highest removal efficiency was with wood walls (46.4\%); the second-highest removal efficiency was for PVC walls (40.9\%); and, the lowest removal efficiency was for cement-paint walls (27.4\%). The removal efficiency of $300 \mathrm{~nm}$ particles by natural decay was between $21 \%$ and $40 \%$ of overall removal efficiency. The percentage of removal efficiency for $30 \mathrm{~nm}$ particles by natural decay was between $43 \%$ and $63 \%$ of overall removal efficiency. These results proved that the removal rate of $30 \mathrm{~nm}$ particles by natural decay was higher than the removal rate of $300 \mathrm{~nm}$ particles by natural decay.

\subsection{Half concentration time}

Fig. 8 plots the half concentration time $\left(T_{50}\right)$ of targeted particles declining by natural decay and NAI application. The half concentration time $\left(T_{50}\right)$ was obtained from the following equations:

$$
C_{\mathrm{t}}=C_{0} \exp (-k t)
$$




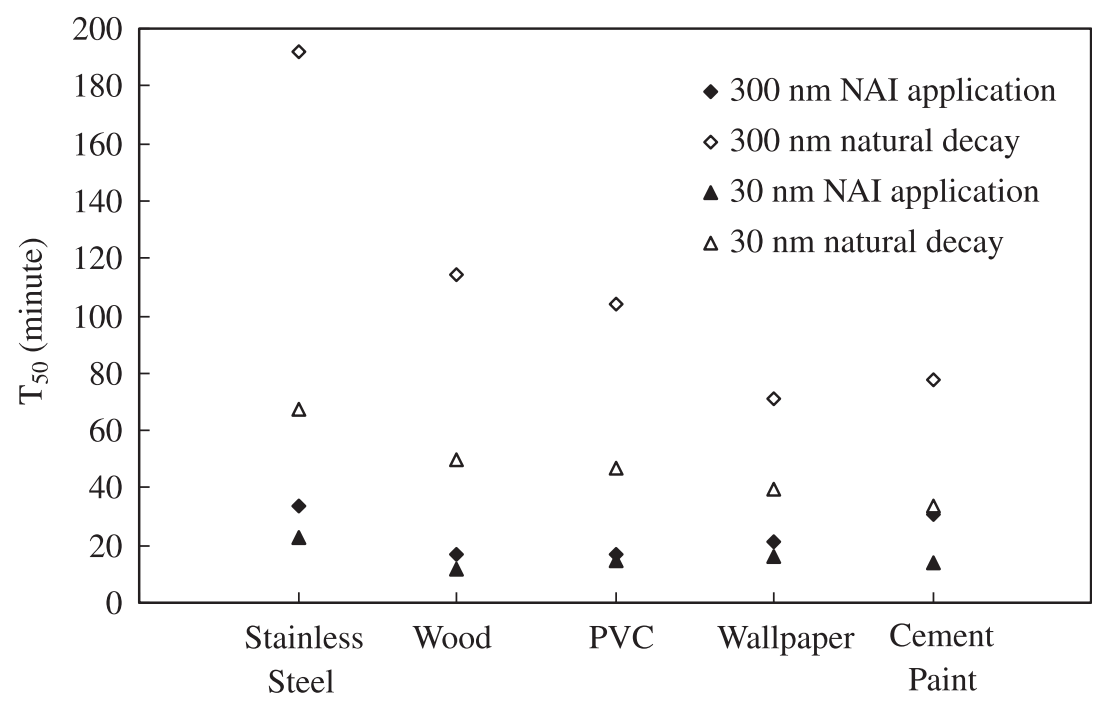

Wall surface material

Fig. 8. Half concentration time ( $\left.T_{50}\right)$ of 300 and $30 \mathrm{~nm}$ particles with natural decay and NAI application at various particle sizes and different wall surface materials.

$$
\begin{aligned}
& 0.5 C_{0}=C_{0} \exp \left(-k T_{50}\right), \\
& T_{50}=0.693 k^{-1},
\end{aligned}
$$

where $C_{0}$ and $C_{\mathrm{t}}$ are the particle concentrations at initial time and $t\left(\right.$ number $\left.\mathrm{cm}^{-3}\right) ; t$ is the residence time (min); $k$ is the decay coefficient, including $k_{\mathrm{n}}$ and $k_{\mathrm{a}}\left(\mathrm{min}^{-1}\right) ; T_{50}$ is the time needed for particle concentration reduced to half of initial particle concentration (min). The results indicated that the $T_{50}$ of $30 \mathrm{~nm}$ particles was smaller than the $T_{50}$ of $300 \mathrm{~nm}$ when NAI generator was operated. Most of $T_{50}$ were smaller than $20 \mathrm{~min}$, except $T_{50}$ for $300 \mathrm{~nm}$ particles in stainless steel and cement paint walls, and $T_{50}$ of $30 \mathrm{~nm}$ particles in stainless steel walls. The $T_{50}$ of $300 \mathrm{~nm}$ particles was very close to $T_{50}$ of $30 \mathrm{~nm}$ particles in wood, PVC and wallpaper walls. For $30 \mathrm{~nm}$ particles with natural decay, the $T_{50}$ for stainless steel walls was approximately $1 \mathrm{~h}$; the $T_{50}$ for the other walls were around $40 \mathrm{~min}$. For $300 \mathrm{~nm}$ particles with natural decay, the $T_{50}$ were all greater than $1 \mathrm{~h}$. The $T_{50}$ of $300 \mathrm{~nm}$ particles for wallpaper and cement paint walls were approximately $70 \mathrm{~min}$; the $T_{50}$ of $300 \mathrm{~nm}$ particles for wood and PVC walls were about $100 \mathrm{~min}$; the highest $T_{50}$ of $300 \mathrm{~nm}$ particles was markedly close to $200 \mathrm{~min}$ for stainless steel walls.

\section{4. $E C R$}

The effective cleaning rate (ECR) (Offermann et al., 1985) is defined as the difference between the decay coefficient of particle concentration with NAI and that without NAI, multiplied by the volume of the testing chamber. Although the calculation of ECR is similar to that of clean air delivery rate (CADR) (ANSI/AHAM AC-1, 1988), the CADR has a specific meaning and is used in an efficiency standard established by Association of Home Appliance Manufacturers (AHAM). Therefore, ECR is used herein. 
Table 3

Effective cleaning rate (ECR) of NAI application at various particle sizes and different wall surface materials (standard deviation less than $8 \%$ )

\begin{tabular}{lll}
\hline Wall surface material & ECR $(\mathrm{Lpm})$ & \\
\cline { 2 - 3 } & $300 \mathrm{~nm}$ & $30 \mathrm{~nm}$ \\
\hline Stainless steel & $16.6 \pm 1.1$ & $20.1 \pm 1.5$ \\
Wood & $34.6 \pm 1.6$ & $41.4 \pm 1.8$ \\
PVC & $33.3 \pm 1.3$ & $30.4 \pm 1.1$ \\
Wallpaper & $27.0 \pm 1.7$ & $27.7 \pm 1.7$ \\
Cement paint & $14.8 \pm 1.2$ & $30.3 \pm 2.0$ \\
\hline
\end{tabular}

Table 3 presents the ECRs of 300 and $30 \mathrm{~nm}$ particles in various wall materials when NAI is applied. The $\mathrm{ECR}(\mathrm{Lpm})$ is determined using the following equation:

$$
\mathrm{ECR}=\left(k_{\mathrm{a}}-k_{\mathrm{n}}\right) \times V_{\text {chamber }},
$$

where $k_{\mathrm{a}}$ and $k_{\mathrm{n}}$ are the decay coefficients associated with NAI and natural decay $\left(\min ^{-1}\right)$, respectively; $V_{\text {chamber }}$ is the volume of the reaction chamber $\left(1.0 \mathrm{~m}^{3}\right)$. Table 2 presents the calculated value of $k_{\mathrm{a}}-k_{\mathrm{n}}$. The values of ECR were calculated from the decay coefficients, and the standard deviations of ECR were less than $8 \%$. In this study, ECR indicates the overall effect of the combined mechanisms of the NAI reaction and the wall surface materials. The results show that the highest ECR of $300 \mathrm{~nm}$ particles was 34.6 Lpm, for the wood wall; the second-highest ECR was for PVC walls $(33.3 \mathrm{Lpm})$, and the lowest ECR was for cement-paint walls $(14.8 \mathrm{Lpm})$. The ECR of $300 \mathrm{~nm}$ particles for wood walls was 2.3 times that for cement-paint walls. For $30 \mathrm{~nm}$ particles, the highest ECR was $41.4 \mathrm{Lpm}$ for wood walls; the second-highest ECR was for PVC walls $(30.4 \mathrm{Lpm})$, and, the lowest ECR was for stainless steel walls (20.1 Lpm). The ECR of $30 \mathrm{~nm}$ particles for wood walls was 2.1 times that for stainless steel walls. The results of ECR reveal that the wood and PVC wall materials were promoted the removal of particles with NAIs. Stainless steel was the least effective of the five wall materials in the removal of particles using NAIs. The ECR obtained using NAI and a wallpaper wall was approximately $27 \mathrm{Lpm}$ for both 300 and $30 \mathrm{~nm}$ particles. For cement paint walls, the ECR of $30 \mathrm{~nm}$ particles $(30.3 \mathrm{Lpm})$ around double that of $300 \mathrm{~nm}$ particles $(14.8 \mathrm{Lpm})$, indicating that the NAI reaction for $30 \mathrm{~nm}$ particles was more effective than that for $300 \mathrm{~nm}$ particles in remove particles from the cement-painted walls of a chamber. The $k_{\mathrm{n}}$ of cement paint is exceeds that of the other wall materials both for 300 and $30 \mathrm{~nm}$ particles. The roughness of cement paint exceeds that of the other wall materials, and may be responsible for the relatively high natural decay coefficient $\left(k_{\mathrm{n}}\right)$. Therefore, the ECR of cement paint associated with a high natural decay coefficient $\left(k_{\mathrm{n}}\right)$ is low.

The ECRs for $300 \mathrm{~nm}$ particles followed the order wood $>$ PVC $>$ wallpaper $>$ stainless steel $>$ cement paint; those for $30 \mathrm{~nm}$ particles followed the order wood $>\mathrm{PVC} \cong$ cement paint $>$ wallpaper $>$ stainless steel. The electrical characteristics of wall materials were surface resistivity $(\Omega)$ wood $\left(3.97 \times 10^{15}\right)>$ PVC $\left(3.11 \times 10^{15}\right)>$ wallpaper $\left(1.03 \times 10^{15}\right)>$ cement paint $\left(5.96 \times 10^{11}\right) \gg$ stainless steel (conductor) and electrical conductivity $(\Omega \mathrm{m})^{-1}$ : wood $\left(1.24 \times 10^{-15}\right)<\mathrm{PVC}(2.38 \times$ $\left.10^{-15}\right)<$ wallpaper $\left(4.17 \times 10^{-15}\right)<$ cement paint $\left(2.54 \times 10^{-9}\right) \ll$ stainless steel $\left(1.4 \times 10^{6}\right)$ (Callister, 2000). These results reveal that the values of ECR are approximately related to surface resistivity and 
electrical conductivity. The roughness of the surface of cement paint may affect the ECRs for 300 and $30 \mathrm{~nm}$ particles.

\section{Conclusions}

The influence of wall surface materials on the removal of particles by NAIs was studied. Five wall materials, stainless steel, wood, PVC, wallpaper and cement paint, were used in experiments on natural decay and decay with NAI. The target particles were 300 and $30 \mathrm{~nm}$ monodispersed solid $\mathrm{NaCl}$ particles that reacted with NAI at a concentration of 3000-5000 ion $\mathrm{cm}^{-3}$ in the test chamber. The experimental data indicate that the wall material influenced the removal of particles by natural decay and when NAI is used. The decay coefficients of natural decay and NAI-promoted decay varied with the wall material. The use of an NAI generator increased the removal efficiency of both 300 and $30 \mathrm{~nm}$ target particles. The overall removal efficiency was the highest in the chambers with wood and PVC walls, being over $60 \%$ and $80 \%$ for 300 and $30 \mathrm{~nm}$ particles, respectively. The time to half concentration of target particles $\left(T_{50}\right)$ was typically under $20 \mathrm{~min}$, except for the stainless steel and cement-painted walls. The highest ECRs were 34.6 and $41.4 \mathrm{Lpm}$ for 300 and $30 \mathrm{~nm}$ particles, respectively, in the chamber with wood walls. The second-highest ECR was associated with PVC walls and the lowest ECR was obtained with cementpainted and stainless steel walls for 300 and $30 \mathrm{~nm}$ particles, respectively. NAI air cleaning technology was most effective when the walls were made of wood or PVC. The roughness and electrical properties of wall materials may affect the mechanisms.

\section{Acknowledgements}

The authors would like to thank the National Science Council of the Republic of China for financially supporting this research under Contract no. NSC 93-2211-E-002-028.

\section{References}

Adachi, M., Kousaka, Y., \& Okuyama, K. (1985). Unipolar and bipolar diffusion charging of ultrafine aerosol particles. Journal of Aerosol Science, 16(2), 109-123.

Association of Home Appliance Manufacturers (1988). Portable cord-connected air cleaner performance measurement standard. ANSI/AHAM AC-1.

ASTM D5116-97 (1997). Standard guide for small-scale environmental chamber determinations of organic emissions from indoor materials/products.

Benes, M., \& Holub, R. F. (1996). Aerosol wall deposition in enclosures investigated by means of a stagnant layer. Environment International, 22(Suppl. 1), S883-S889.

Callister, W. D. (2000). Materials science and engineering-an introduction (5th ed.) (pp. 812-815). New York: Wiley.

Cooper, G., Langer, G., \& Rosinski, J. (1979). Submicron aerosol losses in aluminized Mylar bags. Journal of Applied Meteorology, 18, 57-68.

Crump, J. G., Flagan, R. C., \& Seinfeld, J. H. (1983). Particle wall loss rates in vessels. Aerosol Science and Technology, 2(3), 303-309.

Crump, J. G., \& Seinfeld, J. H. (1981). Turbulent deposition and gravitational sedimentation of an aerosol in a vessel of arbitrary shape. Journal of Aerosol Science, 12(5), 405-415.

Daniels, S. L. (2002). On the ionization of air for removal of noxious effluvia. IEEE Transactions on Plasma Science, 30, $1471-1481$. 
Goldstein, N. I., Goldstein, R. N., \& Merzlyak, M. N. (1992). Negative air ions as a source of superoxide. International Journal of Biometeorology, 36, 118-122.

Grabarczyk, Z. (2001). Effectiveness of indoor air cleaning with corona ionizers. Journal of Electrostatics, 51-52, $278-283$.

John, W. (1995). Particle-surface interactions: charge transfer, energy loss, resuspension, and deagglomeration. Aerosol Science and Technology, 23, 2-24.

Kondrashova, M. N., Grigorenko, E. V., Tikhonov, A. N., Sirota, T. V., Temnov, A. V., Stavrovskaja, I. G. et al. (2000). The primary physico-chemical mechanism for the beneficial biological/medical effects of negative air ions. IEEE Transactions on Plasma Science, 28, 230-237.

Kosenko, E. A., Kaminsky, Yu. G., Stavrovskaya, I. G., Sirota, T. V., \& Kondrashova, M. N. (1997). The stimulatory effect of negative air ions and hydrogen peroxide on the activity of superoxide dismutase. FEBS Letters, 410, 309-312.

Krueger, A. P., \& Reed, E. J. (1976). Biological impact of small air ions. Science, 193, 1209-1213.

Lee, B. U., Yermakov, M., \& Grinshpun, S. A. (2004a). Removal of fine and ultrafine particles from indoor air environments by the unipolar ion emission. Atmospheric Environment, 38, 4815-4823.

Lee, B. U., Yermakov, M., \& Grinshpun, S. A. (2004b). Unipolar ion emission enhances respiratory protection against fine and ultrafine particles. Journal of Aerosol Science, 35, 1359-1368.

Luts, A., \& Salm, J. (1994). Chemical composition of small atmospheric ions near the ground. Journal of Geophysical Research, 99(D5), 10781-10785.

Mayya, Y. S., Sapra, B. K., Khan, A., \& Sunny, F. (2004). Aerosol removal by unipolar ionization in indoor environments. Journal of Aerosol Science, 35, 923-941.

McMurry, P. H., \& Rader, D. J. (1985). Aerosol wall losses in electrically charged chambers. Aerosol Science and Technology, 4, 249-268.

Nomura, Y., Hopke, P. K., Fitzgerald, B., \& Mesbah, B. (1997). Deposition of particles in a chamber as a function of ventilation rate. Aerosol Science and Technology, 27, 62-72.

Offermann, F. J., Sextro, R. G., Fisk, W. J., Grimsrud, D. T., Nazaroff, W. W., Nero, A. V. et al. (1985). Control of respirable particles in indoor air with portable air cleaners. Atmospheric Environment, 19, 1761-1771.

Oh, H., Park, H., \& Kim, S. (2004). Effects of particle shape on the unipolar diffusion charging of nonspherical particles. Aerosol Science and Technology, 38, 1045-1053.

Okuyama, K., Kousaka, Y., Yamamoto, S., \& Hosokawa, T. (1986). Particle loss of aerosols with particle diameter between 6 and $2000 \mathrm{~nm}$ in stirred tank. Journal of Colloid and Interface Science, 110(1), 214-223.

Park, S. H., Kim, H. O., Han, Y. T., Kwon, S. B., \& Lee, K. W. (2001). Wall loss rate of polydispersed aerosols. Aerosol Science and Technology, 35, 710-717.

Parts, T.E., Luts, A. (2004). Observed and simulated effects of certain pollutants on small air ion spectra: I. Positive ions. Atmospheric Environment, 38, 1283-1289.

Ryushi, T., Kita, I., Sakurai, T., Yasumatsu, M., Isokawa, M., Aihara, Y. et al. (1998). The effect of exposure to negative air ions on the recovery of physiological responses after moderate endurance exercise. International Journal of Biometeorology, 41 , 132-136.

Unger, L., Boulaud, D., \& Borra, J. P. (2004). Unipolar field charging of particles by electrical discharge: Effect of particle shape. Journal of Aerosol Science, 35, 965-979.

Wiedensohler, A., Büscher, P., Hansson, H. C., Martinsson, B. G., Stratmann, F., Ferron, G. et al. (1994). A novel unipolar charger for ultrafine aerosol particles with minimal particle losses. Journal of Aerosol Science, 25(4), 639-649.

Wu, C. C., \& Lee, G. W. M. (2003). The temporal aerosol size distribution in indoor environment with negative electric discharge. Journal of Aerosol Science, 34, S999-S1000. 